\title{
ANNONACEAE E LAURACEAE DA FORMAÇÃO ENTRE-CÓRREGOS (PALEÓGENO) NA BACIA DE AIURUOCA: IMPLICAÇÕES PALEOCLIMÁTICAS
}

\author{
SÍLVIAGOUVEIAFRANCO-DELGADO \\ Lab. de Geociências, UnG, Praça Teresa Cristina, 1, 07023-070, Guarulhos, SP, Brasil. silgoudel@uol.com.br \\ MARY ELIZABETHC. BERNARDES-DE-OLIVEIRA \\ Instituto de Geociências, USP, Rua do Lago, 562, 05508-900, São Paulo, SP, Brasil.maryeliz@usp.br
}

\begin{abstract}
RESUMO - As tafofloras paleógenas brasileiras ocorrem, preferencialmente, em bacias sedimentares interioranas do tipo "rift" continental mesozóico-cenozóico. A bacia de Aiuruoca, localizada em Minas Gerais próximo à divisa com os estados de São Paulo e Rio de Janeiro, corresponde a este tipo de ocorrência. Nessa bacia, foram identificadas as presenças de Annona sp e Nectandra sp., sob a forma de impressões ou carbonizações foliares em folhelhos papiráceos da Formação Entre-Córregos, aflorantes à margem do córrego homônimo. Essa tafoflora, com base em dados palinológicos, tem sido datada como de idade Eoceno/Oligoceno. A presença dos gêneros Annona e Nectandra é mais um indicativo do domínio da floresta pluvial Atlântica, com pelo menos dois estratos naquela área durante o Paleógeno.
\end{abstract}

Palavras-chave: Annona, Nectandra, tafoflora paleógena, bacia de Aiuruoca, Brasil.

ABSTRACT - ANNONACEAE AND LAURACEAE OF THE ENTRE-CÓRREGOS FORMATION (PALEOGENE), IN THE AIURUOCA BASIN: PALEOCLIMATICAL IMPLICATIONS. The Brazilian Paleogene taphofloras occur preferentially in the interior sedimentary basins related to the Mesozoic-Cenozoic continental rift. The Aiuruoca Basin, located in the Minas Gerais State near the boundaries with the states of São Paulo and Rio de Janeiro, is this kind of basin. In Aiuruoca basin, Annona sp and Nectandra sp. were identified among the foliar material as carbonization and impressions on papyraceous shales of the EntreCórregos Formation, cropping out at the homonymous creek margin. Based on palynological dates, this taphoflora has been dated as Eocene-Oligocene. The presence of the genera Annona and Nectandra in this taphoflora is a strong evidence for dominance of the Atlantic Rain Forest, with at least two strata in that area during the Paleogene.

Key words: Annona, Nectandra, Paleogene taphoflora, Aiuruoca basin, Brazil.

\section{INTRODUÇÃO}

O Paleógeno, no Brasil, é um dos períodos, mais desconhecido paleontologicamente e de documentação esparsa, embora abundante. Apresenta depósitos de três categorias distintas: as grandes coberturas das bacias sedimentares paleozóicas, como a que ocorre na bacia Amazônica; aqueles pertencentes às bacias do tipo "rift" do interior e os depósitos localizados em bacias do tipo "rift" marginais.

Romero (1986) havia ressaltado que todas as tafofloras neocretáceas e paleógenas reconhecidas na América do Sul, até então, localizavam-se em áreas costeiras de várias bacias marinhas. Teriam sido sepultadas em ambientes deltaicos, pantanosos costeiros e lagunares. Entretanto, o levantamento das tafofloras paleógenas brasileiras, conhecidas mais recentemente, tem evidenciado sua ocorrência mais freqüente em bacias tipo "rift" do interior, distintamente das demais tafofloras sul-americanas de idade equivalente. Entre essas bacias citam-se as bacias de Itaboraí (RJ), Bonfim, Taubaté, São Paulo (SP) e as bacias de Gandarela, Fonseca e de Aiuruoca (MG).

Este trabalho dá início a uma série de contribuições referentes a fitofósseis paleógenos inéditos, ocorrentes na bacia de Aiuruoca (MG). Dentre as formas reconhecidas por Franco-Delgado (2002) nessa bacia, verificam-se: Annona sp, Nectandra sp, Apeiba sp, Luehea sp, Passiflora sp, Caesalpinia cf. C. echinata, Machaerium sp, Campomanesia sp, Eugenia sp, Myrciaria sp, Psidium sp e Sapindus sp. Neste primeiro artigo, serão abordadas apenas as formas relacionadas às magnoliídeas. A subclasse Magnoliidae está representada, na tafoflora de Aiuruoca, por formas lenhosas pertencentes às ordens Magnoliales (gênero Annona) e Laurales (gênero Nectandra). 


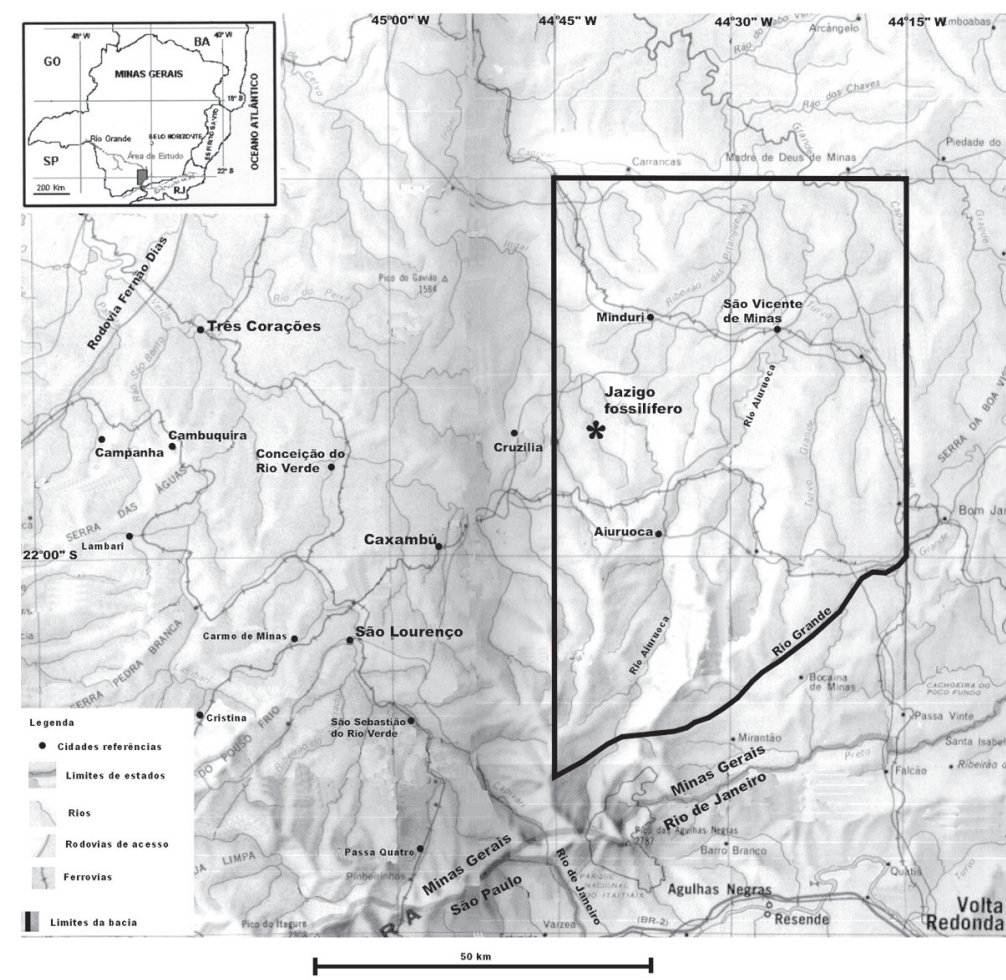

Figura 1. Mapa de localização geográfica da bacia de Aiuruoca (modificado de Franco-Delgado, 2002).

Figure 1. Location map of the Aiuruoca basin (modified from FrancoDelgado, 2002).

\section{BACIA DE AIURUOCA}

A bacia sedimentar paleógena de Aiuruoca está localizada, aproximadamente, entre os paralelos $21^{\circ} 30^{\prime} \mathrm{S}$ e $22^{\circ} 15^{\prime} \mathrm{S}$ e os meridianos $44^{\circ} 15^{\prime} \mathrm{W}$ e $44^{\circ} 45^{\prime} \mathrm{W}$, no sul do Estado de Minas Gerais, próximo aos limites com os estados de São Paulo e Rio de Janeiro (Figura 1). Essa bacia foi descoberta e descrita por Santos (1999) e encontra-se situada no Planalto do Alto Rio Grande, limitada ao norte pela serra de Mindurí e ao sul pela serra da Mantiqueira, apresentando uma superfície de $3.400 \mathrm{Km}^{2}$ e altitude média de 1.100 metros. Segundo aquela autora, os afloramentos dessa bacia são raros e estão presentes em áreas de altitude entre 1.020 e 1.168 metros, com espessuras de sedimentos que oscilam entre decamétricas e centimétricas, em conseqüência do avançado grau de erosão.

A bacia é composta, informalmente, por duas unidades estratigráficas: Formação Pinheirinho, a qual assenta-se sobre o embasamento cristalino e corresponde à fácies fanglomerática de sistema deposicional tipo leque aluvial; e Formação EntreCórregos, constituída por folhelhos que correspondem à fácies lacustre da bacia. Essa última unidade apresenta níveis fossilíferos contendo folhas, caules, pequenos frutos, peixes, anfíbios, insetos e coprólitos (Figura 2). A área-tipo foi designada à margem do córrego Entre-Córregos, por apresentar estratos das duas formações.
Por seu conteúdo palinológico, onde são observadas as presenças de formas tais como: Biretisporites crassilabratus, Echimonocolpites sp., Malvacearumpollis (Echiperiporites stelae), E. tschudyi, Echitricolpites sp, Gleichenidites (Radiastisporis) radiatus, Polotricolporites mocinni, Polyadopollenites (Acaciopollenites) myriosporites, Polypodiisporites ornatus, Proteacidites dehaani, Psilatricolporites operculatus, Quadraplanus sp, Retitricolporites medius, Syncolporites lisamae, Ulmoideipites krempii e Verrucatosporites tennelis, Garcia et al.(2000) atribuíram uma idade eocena/oligocena à Formação Entre-Córregos.

\section{MATERIALE MÉTODOS}

O afloramento de onde provêm os fitofósseis corresponde a uma seção da Formação EntreCórregos e está situado à margem esquerda do córrego Entre-Córregos, a 1.080 metros de altitude (Figura 1).

O material aqui descrito é constituído de um exemplar foliar preservado por carbonização e outro por impressão e suas respectivas contra-impressões. Estão numerados como UnG/3T-03 a/b e UnG/3T-04a/ b e depositados na coleção científica do Laboratório de Geociências da Universidade Guarulhos (UnG). tendo sido coletados pela equipe do referido laboratório, incluindo as autoras.

O afloramento de procedência desses fitofósseis pode ser assim descrito (Figura 3): uma camada basal de 1,42 m de espessura de folhelho papiráceo argiloso, cinza médio, com abundância de pipídeos, raros fósseis vegetais, onde predominam caules de maior porte ( 2 a $3 \mathrm{~cm}$ de diâmetro) e, em pequena quantidade, folhas e frutos, além de insetos, peixes e penas de aves; sobrepõe-se uma camada de $0,10 \mathrm{~m}$ de espessura de ritmito onde se alternam lâminas de fo-

\begin{tabular}{|c|c|c|c|}
\hline LITOFÁCIES & $\begin{array}{c}\text { SISTEMAS } \\
\text { DEPOSICIONAIS }\end{array}$ & LITOESTRATIGRAFIA & IDADE \\
\hline $\begin{array}{l}\text { Cobertura areno-argilosa } \\
\text { apresentando conglomerados } \\
\text { basais }\end{array}$ & LEQUES ALUVIAIS & & PLEISTOCENO \\
\hline $\begin{array}{l}\text { Diamictitos roxos e brechas } \\
\text { sedimentares }\end{array}$ & $\begin{array}{l}\text { LEQUES ALUVIAIS } \\
\end{array}$ & FORMAÇÃO PINHEIRINHO & ? \\
\hline $\begin{array}{l}\text { Folhelho cinza-escuro } \\
\text { apresentando fosseses diversos, } \\
\text { além de intercalaços de } \\
\text { argilitito }\end{array}$ & LACUSTRE & $\begin{array}{l}\text { FORMAÇ̃̃O } \\
\text { ENTRE-CÓRREGOS }\end{array}$ & $\begin{array}{l}\text { EOCENO- } \\
\text { OLIGOCENO }\end{array}$ \\
\hline $\begin{array}{l}\text { Diamictitos roxos areno- } \\
\text { argilosose e evserdeados com } \\
\text { matriz lamitica, além de } \\
\text { brechas sedimentares e } \\
\text { arcóseos }\end{array}$ & \multirow{3}{*}{ LEQUES ALUVIAIS } & \multirow{3}{*}{ FORMAÇÃO PINHEIRINHO } & \multirow{2}{*}{ 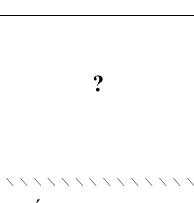 } \\
\hline $\begin{array}{c}\text { Conglomerados lateriticos, } \\
\text { com intercalacoes de lentes de } \\
\text { diamictitos }\end{array}$ & & & \\
\hline $\begin{array}{l}\text { Gnaisses, migmatitos e xistos } \\
\text { diversos }\end{array}$ & & & PRÉ-CAMBRIANO \\
\hline
\end{tabular}

Figura 2. Esquema da coluna litoestratigráfica da bacia de Aiuruoca (modificado de Santos, 1999).

Figure 2. Lithostratigraphical column of the Aiuruoca basin (modified from Santos, 1999). 
lhelho e arenito fino, argiloso, micáceo, rico em fitofósseis, principalmente folhas, a qual corresponde ao nível em que a maior parte dos fitofósseis estudados foi coletada; acima, essa camada passa a um folhelho papiráceo com espessura de 0,24 m, micáceo, cinza escuro, pobre em fitofósseis, muito alterado, com intromissões de raízes atuais; por último, tem-se um solo orgânico argiloso com 0,60 m de espessura, escuro e permeado por raízes atuais.

O ritmito, onde a assembléia ocorre, apresenta maior abundância de fósseis em sua porção basal. Os espécimes estão mais bem preservados nas lâminas argilosas do que nas arenosas desse ritmito.

Após preparação mecânica, os fitofósseis, foram observados em estereomicroscópio e desenhados sob câmara clara, visando observação e documentação gráfica do padrão de venação e de outros detalhes morfológicos. A seguir, foram fotografados sob iluminação natural e com "flash" vertical devido à ausência de superfície em relevo e o baixo contraste de cor entre a matriz e os espécimes.

As dimensões lineares e angulares do limbo e venação foram mensuradas através da utilização de paquímetro e transferidor sobre o fóssil ou sobre o seu desenho. As áreas da superfície foliar foram obtidas utilizando-se planímetro (de cálculo de área em plantas e mapas), sobre as cópias feitas em decalque dos fósseis com grafite macia (6B) em papel vegetal e também pelo método de Ash et al. (1999:16), isto é, comprimento x largura x 2/3. Na classificação dos espécimes, segundo sua área foliar, foi utilizado o sistema de Raunkiaer (1934). Para caracterização da venação e morfobiometria foliar empregaram-se os métodos e designações propostos no manual de arquitetura foliar de Ash et al. (1999).

A sistemática das famílias angiospérmicas foi feita segundo Cronquist (1988) e, para taxa superiores a ordem, foi seguida aquela apresentada por Raven et al. (2001).

$\mathrm{Na}$ identificação, os desenhos e fotos obtidos foram utilizados para comparações com espécimes da flora atual e com figuras e descrições da literatura. O material atual foi obtido através de doação do Herbário Municipal de São Paulo à Universidade Guarulhos, e através de observações de material pertencentes ao Herbário do Departamento de Botânica do Instituto de Biociências da USP. Materiais comparativos de Annona cacans Warm e de Nectandra megapotamica (Spreng.) foram clarificados, coloridos e montados em lâminas, conforme procedimento proposto por Foster (1952) e descrito por Dutra \& Stranz (2002), no Laboratório de Paleobotânica e Palinologia do IGc/USP.

\section{SISTEMÁTICAPALEONTOLÓGICA}

\author{
Subclasse MAGNOLIIDAE \\ Ordem MAGNOLIALES \\ Família ANNONACEAE
}

Annona sp.

(Figuras 4 A-D)

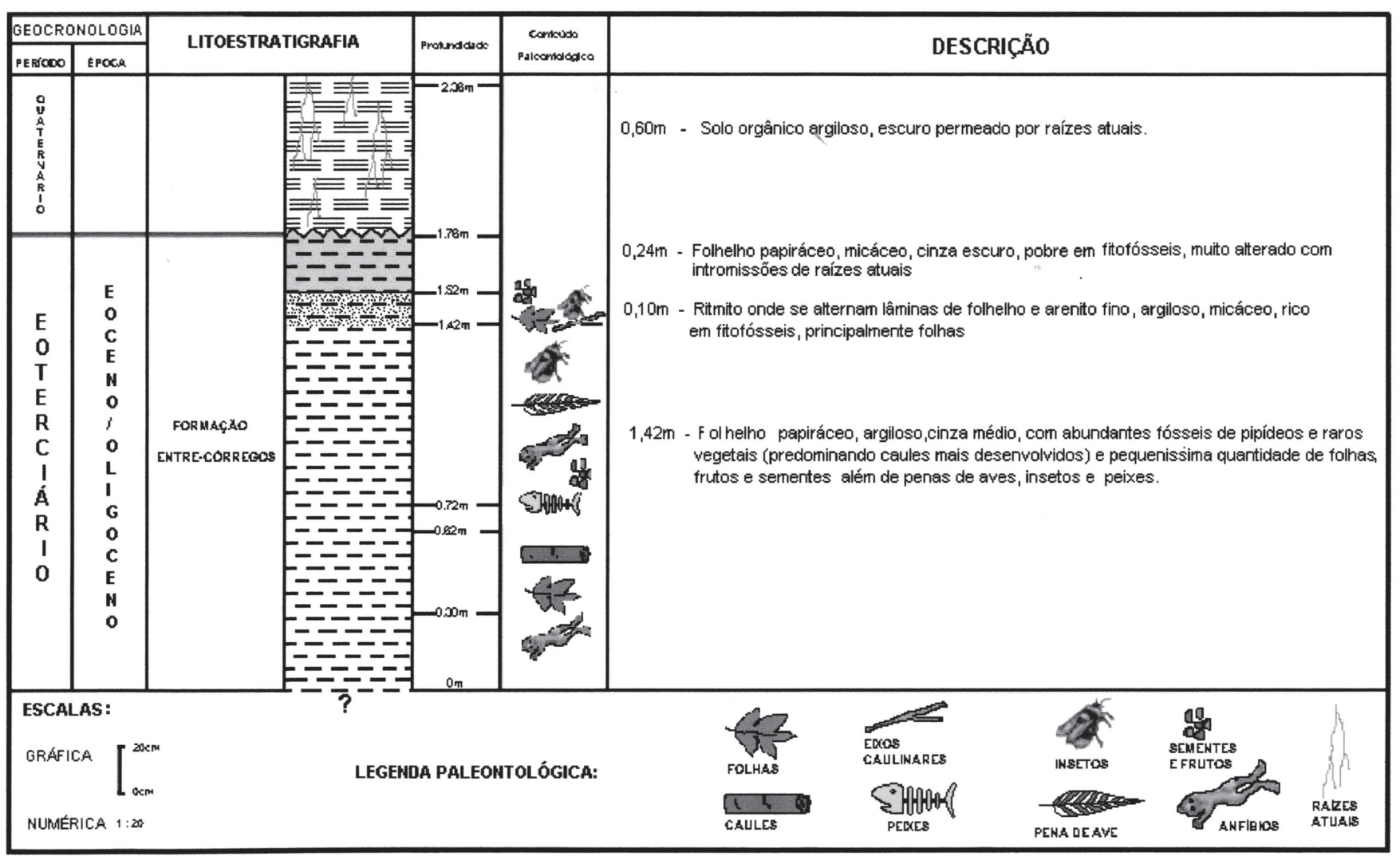

Figura 3. Seção litoestratigráfica, cronológica e paleontológica do afloramento da Formação Entre-Córregos.

Figure 3. Lithostratigraphical, chronological and paleontological section of the Entre-Córregos Formation outcrop. 
Espécimes estudados. UnG/3T-03a,b.

Procedência. Afloramento na margem esquerda do córrego Entre-Córregos, NW da cidade de Aiuruoca (MG). Formação Entre-Córregos, bacia de Aiuruoca.

Idade. Eoceno/Oligoceno.

Descrição. Compressão de folha simples, de pecíolo marginal normal, tipo microfila $\left(234,24 \mathrm{~mm}^{2}\right)$, formato obovado $(1,6: 1)$, medindo $24,4 \mathrm{~mm}$ de comprimento por $14,4 \mathrm{~mm}$ de largura máxima, localizada a 13,5 mm da base, isto é, acima da metade da distância entre o ápice e a base; lâmina simétrica; base cuneada, com ângulo agudo de $72^{\circ}$, ápice obtuso, com ângulo de $92^{\circ}$ e retuso; margem inteira; não lobada; textura papirácea. Preservação da face abaxial da folha com veias salientes. Venação de padrão actinódromo, com ponto de radiação suprabasal das veias primárias, situado a $7 \mathrm{~mm}$ da base. Veias primárias de calibre moderado $(1,6 \%)$. Veia primária mediana (PM) de curso reto e ramificado, formada por um feixe vascular, donde emergem veias primárias laterais (PL) e secundárias (S). Duas veias primárias laterais (PL), de calibre um pouco menor e muito variável, de curso levemente sinuoso, recurvando-se na porção distal (Figuras 4A-D). Venação secundária tipo broquidódroma fraca, emergindo da veia primária mediana ou das primárias laterais, com espaçamento irregular, em ângulos uniformes, agudos estreitos (menores que $45^{\circ}$ ), juntam-se na área marginal numa série de arcos. Veias secundárias distais (SD) emergem a ângulos mais amplos que as proximais (SP). Veia secundária de calibre moderado a fino, de curso reto, recurvado ou sinuoso, unindo-se à secundária subjacente por "loops" reversos. Um ou dois conjuntos de "loops" adicionais, fora do "loop" broquidódromo principal, constituem uma veia intramarginal a certa distância da borda laminar. Não há veia fimbrial embora uma pigmentação mais escura percorra a margem como se fosse um reforço. Veias intersecundárias, quando presentes, são de caráter sinuoso e de calibre variável. Venação terciária do tipo reticulado ao acaso, emergindo de secundárias e terciárias a ângulos variáveis de $45^{\circ}$ a $110^{\circ}$ e de curso sinuoso. Venação quaternária dicotomizante terminando livremente. Talvez sejam as veias de menor calibre e ordem da folha. Emergem a ângulos agudos amplos (mais ou menos $80^{\circ}$ ) a obtusos e terminam em dicotomias no interior de amplas áreas de caráter irregular.

Comparação e discussão. Em algumas espécies atuais do gênero Annona, verifica-se uma acentuada heterofilia entre: a) folhas normais e maiores, de formato elíptico-estreito a oblongo, simétricas e padrão de venação secundária broquidódroma a broquidódroma fraca, com espaçamento irregular (Figuras 4E-F) e b) microfilas de formato elíptico a obovado, de ápice obtuso e retuso, de padrão de venação actinódromo (Figuras 4G-H). Essas microfilas situam-se em posição proximal, quase axilar de ramos e pedúnculos florais (Figuras 5A-B). Permanecem por mais tempo na planta, sendo as primeiras a aparecer, logo após a caducifolia.

O espécime UnG/3T-03a e sua contra-impressão UnG/3T03b (Figura 4A-D) são formas foliares com características arquiteturais e tamanho semelhantes às microfilas do gênero
Annona, apresentando maior semelhança com aquelas da espécie Annona cacans Warm. (Figuras 4G-H), espécie essa bem documentada em Lorenzi (2000).

Essa espécie atual também apresenta microfilas com veia mediana constituída de feixes vasculares de onde emergem veias primárias laterais e secundárias (Figuras 4G-H, 5A-C). As veias secundárias têm comportamento semelhante, recurvando-se para baixo até a secundária subjacente. Outros aspectos semelhantes entre o exemplar fóssil e o atual são: pecíolo inflado, base cuneada, ápice retuso, veias primárias do tipo actinódromo, veias secundárias ligeiramente subopostas, posicionadas abaixo e acima do ponto de radiação das veias primárias e ângulos de emergência das veias secundárias mais abertos na região distal. Nas formas atuais, a margem apresenta um tênue reforço e uma ligeira tendência para enrolar-se. Isto poderia dar uma errônea idéia de veia fimbrial no fóssil, que se pode comprovar pela constatação de ausência de veia emergindo do feixe vascular basal em direção às margens. Logo, a coloração mais escura existente na margem foliar do espécime fóssil está relacionada a esse reforço marginal, melhor percebido na forma clarificada atual (Figura 4E-F).

A venação das folhas de A. cacans apresenta-se recoberta por uma pilosidade de cor acastanhada, não verificada no espécime fóssil, que poderia ser uma adaptação climática a condições atuais ligeiramente mais secas.

Observa-se que, em Annona cacans, as folhas primordiais de um ramo (microfilas) apresentam-se com venação tipicamente actinódroma (Figuras 4G-H, 5A- B). As veias primárias laterais (PL), nas folhas subseqüentes (mesofilas), paulatinamente se tornam decorrentes à primária mediana (PM), assumindo um aspecto paralelinérvio, divergindo em níveis cada vez mais distantes da base até que, num estágio seguinte, se fundem num só feixe vascular central, até certa altura da folha, quando divergem, lateralmente, como secundárias, assumindo, então, venação de padrão broquidódromo (Figuras 4E-F, 5D).

Hickey \& Wolfe (1975) aventam a hipótese de que um padrão actinódromo perfeito poderia evoluir para um actinódromo imperfeito até um padrão pinado (Figura 5D). Desta maneira, pode-se supor que as formas microfilas poderiam representar um estágio evolutivo primitivo em relação às formas mesófilas de um mesmo ramo.

Duarte (1958) registrou a presença de anonáceas na tafoflora paleógena da bacia de Fonseca, em Alvinópolis (MG), identificando no gênero Annona três novas espécies: A. oliveirae, A. lamegoi e A. carnavalii. Estas três formas com venação pinada broquidódroma, típica das formas mesófilas, não permitem comparação com a forma microfila de venação actinódroma aqui estudada. Esse espécime é tão parecido a uma microfila de Annona cacans que talvez pudesse ser designado $A$. cf. A . cacans . Entretanto, considerando tratar-se de forma paleógena e dado o desconhecimento, até o momento, de formas mesofilas de A. cacans, nesse material, bem como de sua parte reprodutiva e anatômica, a identificação torna-se muito insegura. Daí ser melhor designá-la como Annona sp. 

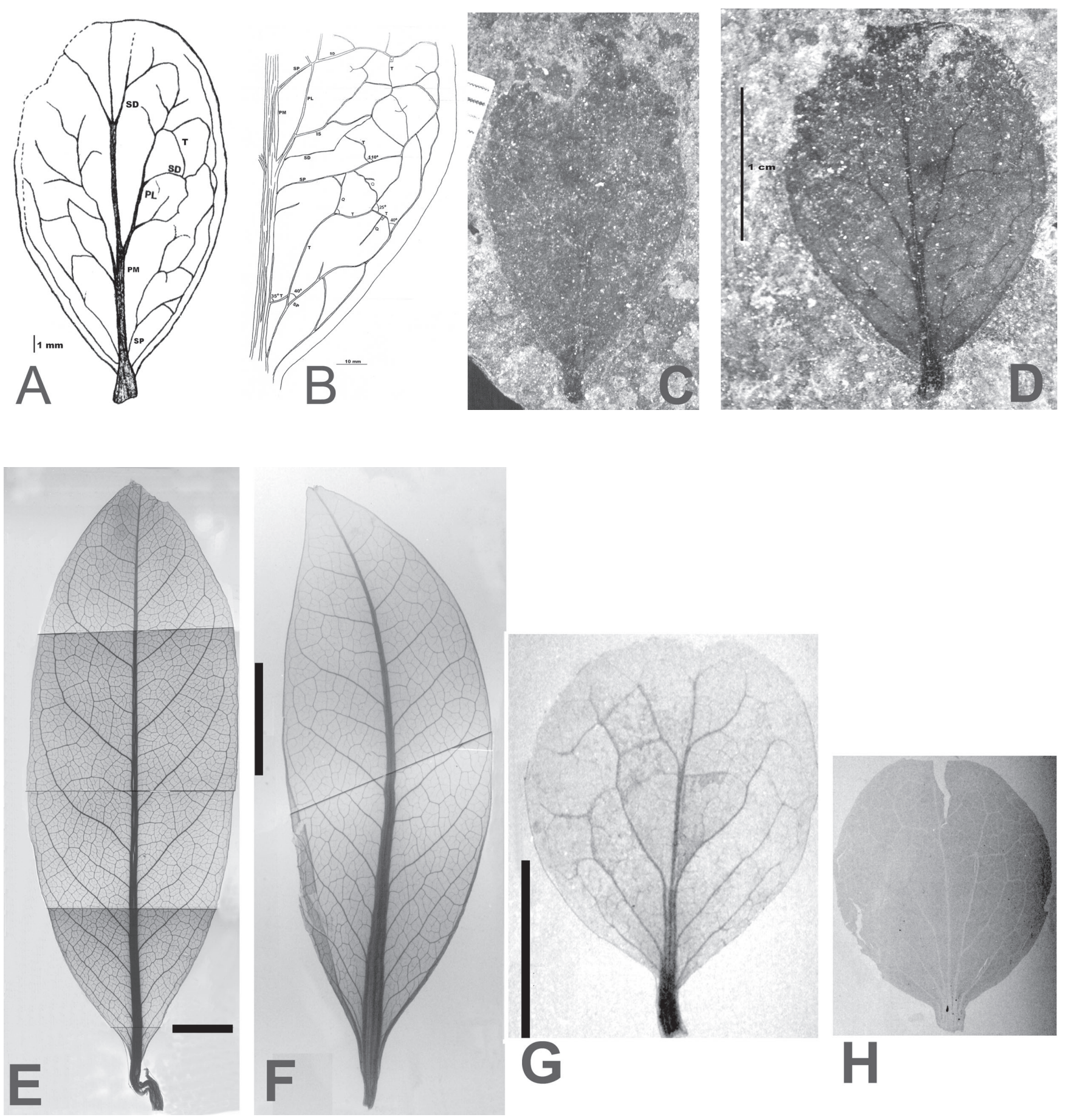

Figura 4. A-D. Annona sp. A. UnG/3T-03b, esquema mostrando venação actinódroma suprabasal. B. Maior detalhe da venação. C. UnG/ 3T-03a, contra-impressão exibindo má preservação da venação. D. UnG/3T-03b, impressão mostrando detalhe da venação primária e secundária broquidódroma fraca. E-H. Annona cacans: E, F. Folhas normais, maiores, clarificadas, exibindo veia principal constituída de um feixe vascular mediano mais nítido e venação secundária broquidódroma. G-H. Microfilas clarificadas, mostrando em veia principal mediana incipiente e as veias principais laterais emergindo em posição suprabasal $(\mathbf{G})$ e venação actinódroma bem nítida $(\mathbf{H})$. Abreviaturas: PM, veia primária mediana, PL, veias primárias laterais, SP, veias secundárias proximais, SD, veias secundárias distais, $T$, veias terciárias, Q, veias quaternárias e seus respectivos ângulos de emergência.

Figure 4. A-D. Annona sp. A. UnG/3T-03b, scheme showing suprabasal actinodromous venation. B. More detailed scheme of venation. C. UnG/ 3T - 03a, counter-part showing a bad preservation of the venation. D. UnG/ 3T - 03b, impression showing details of the primary venation and weak broquidodromous secondary venation. E-H. Annona cacans. E-F. Normal, large and clarified leaves, showing primary vein with an unique median vascular bundle and brochidodromous secondary venation. G-H. Clarified microphylls showing in incipient median principal vein and the lateral principal veins emerging in a suprabasal position $(\mathbf{G})$ and a visible actinodromous venation $(\mathbf{H})$. Abbreviations: PM, median primary vein; PL, lateral primary veins; SP, proximal secondary veins; SD, distal secondary veins; T, tertiary veins; $Q$, quaternary veins and their respective emergence angles. 

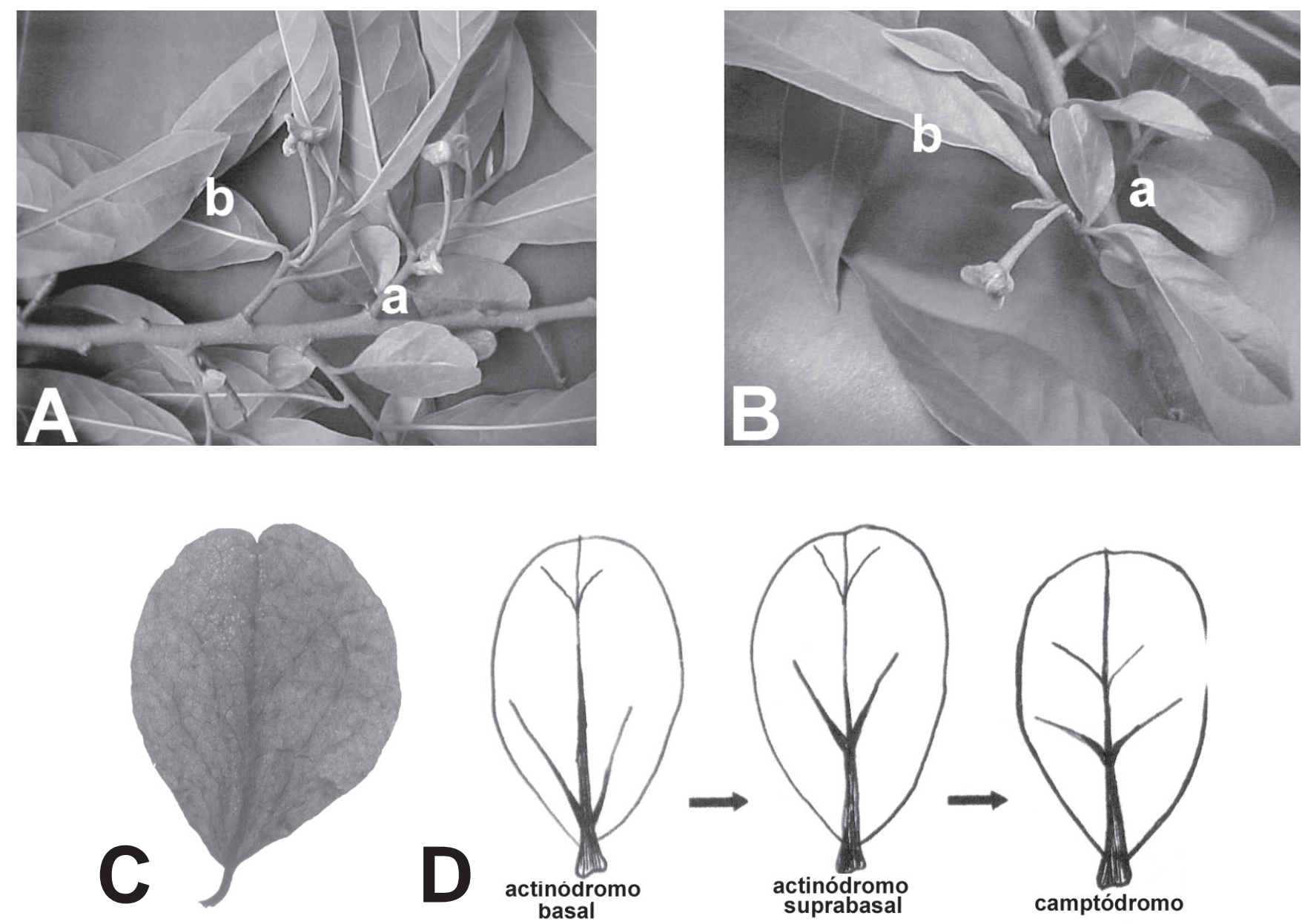

Figura 5. A-C. Annona cacans. A-B. Ramos exibindo microfilas de posição proximal (a) e folhas normais de posição mais distal (b). C. Microfila destacada. D. Esquema evolutivo do padrão: de venação actinódroma gradualmente passaria à actinódroma suprabasal e, posteriormente, à pinada.

Figure 5. A-C. Annona cacans. A-B. Branches showing microphylls in a proximal position (a) and regular leaves in a more distal position (b). C. Isolated microphyll. D. Evolutive scheme of the pattern: actinodromous venation gradually passing to actinodromous suprabasal venation that pass to pinnate.

\section{Ordem LAURALES \\ Família LAURACEAE}

Nectandra $\mathrm{sp}$.
(Figuras 6A-E)

Espécimes estudados. UnG/ 3T-04a e b, depositados na Coleção Científica da UnG.

Procedência. Afloramento da margem esquerda do córrego Entre-Córregos, NW da cidade de Aiuruoca (MG). Formação Entre-Córregos, bacia de Aiuruoca

Idade. Eoceno/Oligoceno.

Descrição. Impressão de folha simples, incompleta, de pecíolo marginal ( $4 \mathrm{~mm}$ por $0,8 \mathrm{~mm}$ ), que se adelgaça rápido no interior do limbo foliar (Figura 6A e B ). Folha tipo microfila (aproximadamente $403 \mathrm{~mm}^{2}$ ), formato oblongo a eliptico (proporção laminar 5:1), medindo $55 \mathrm{~mm}$ de comprimento (inferido) por $11 \mathrm{~mm}$ de largura máxima, com margens aproximadamente paralelas ao longo de todo terço mediano do eixo maior; lâmina de base assimétrica; base convexa, com ângulo agudo de $40^{\circ}$; ápice não preservado. Margem inteira, não lobada; textura papirácea e lâmina glabra. Preservação da face abaxial da folha, com veias pouco salientes. Venação pinada. Veia primária de calibre forte ou robusto $(2,5 \%)$, de curso levemente sinuoso. Veias secundárias tipo broquidódromo fraco, isto é, que se juntam formando uma série de arcos, no geral, sem alcançar a margem. Emergem a um ângulo agudo moderado de $50^{\circ}$ a $55^{\circ}$, em espaçamento decrescente em direção à base. Apresentam calibre moderado a fino e curso uniformemente encurvado, às vezes, levemente sinuoso. Unem-se às secundárias suprajacentes em ângulos variáveis e algumas vezes bifurcam-se antes dessa união, seguindo um dos ramos da dicotomia para a margem. Veias intersecundárias consistindo em simples segmentos sinuosos unidos ou não às suprajacentes localizam-se, aproximadamente, na porção mediana da área intercostal. Outras vezes, num dos 

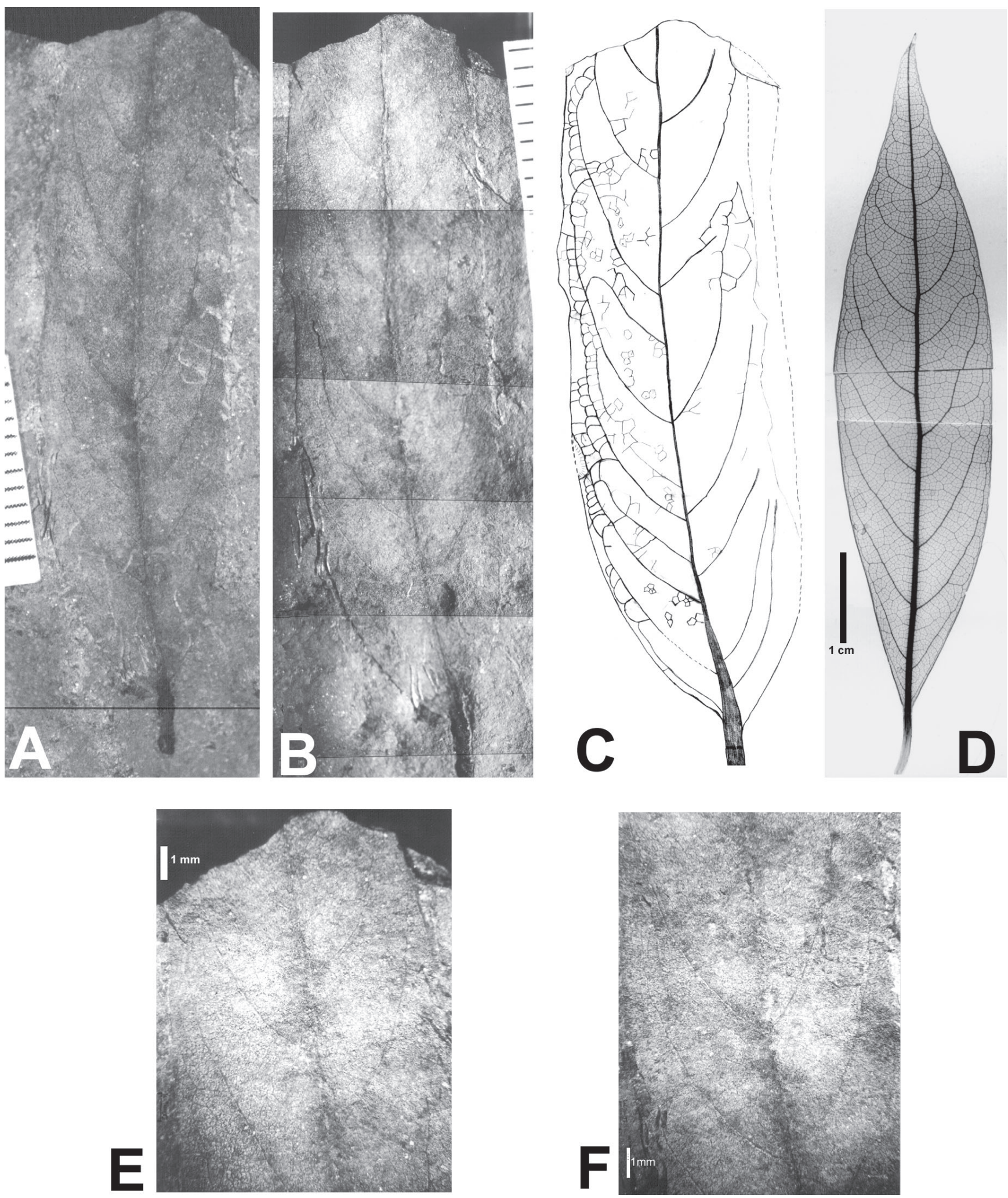

Figura 6. A-E. Nectandra sp. A. UnG/ 3T - 04a. B. UnG/ 3T 04b, contra-impressão. C-E. UnG/ 3T - 04a. C. Detalhe de venação da área mais distal. D. Detalhe de venação da área laminar mediana. E. Desenho da venação observada. F. Nectandra megapotamica. Folha clarificada exibindo venação pinada broquidódroma fraca, formando uma série de pequenos arcos; intersecundárias sinuosas e terciárias de padrão percorrente bifurcado ou reticulado ao acaso, muito finas.

Figure 6. A-E. Nectandra sp. A. UnG/ 3T - 04a. B. UnG/ 3T - 04b, counter-part. C-E. UnG/ 3T - 04a. C. Venation details on the more distal area. D. Venation details on the median laminar area. E. Drawing of observed venation. F. Nectandra megapotamica. Clarified leaf showing a weak brochidodromous pinnate venation, forming a series of short arches and very fine sinuous intersecondary venation and alternate percurrent bifurcate or random reticulate tertiary venation. 
semilimbos, comportam-se diferentemente, constituindo veias terciárias coalescentes. Terciárias percorrentes alternadas, cruzando entre secundárias com uma descontinuidade angular abrupta, em ângulo de emergência de $90^{\circ}$ a $95^{\circ}$; calibre moderado a fino e curso sinuoso constituindo um ângulo obtuso, variável ou inconsistente com a nervura mediana $\left(95^{\circ}\right.$ a $\left.130^{\circ}\right)$. Às vezes, veias terciárias, alternando o padrão percorrente bifurcado com o reticulado ao acaso. Venação quaternária reticulada poligonal regular constituindo polígonos de forma e tamanho similares (Figura 6C-E).

Comparação e discussão. O espécime UnG/3T- 04a e sua contra-impressão UnG/3T-04b (Figura 6A e B) foram identificados como pertencentes à família Lauraceae da ordem Laurales, por apresentarem muitas características inerentes a ela, como: folhas simples, lâmina glabra, venação pinada de padrão broquidódromo fraco, textura papirácea, margem inteira e formato elíptico (Hickey \& Wolfe,1975). Apresenta certa semelhança com Laurophyllum arcuatum Hill (Hill,1986, fig. 3D), do Eoceno de New South Wales, no que se refere à forma geral com base assimétrica, disposição das veias secundárias, basalmente subopostas passando a alternas distalmente, contudo, diferem no tipo de venação secundária que é broquidódroma fraca e não propriamente eucamptódroma como naquela espécie.

Sua venação secundária broquidódroma fraca, suas veias intersecundárias sinuosas, suas veias terciárias alternando o padrão percorrente bifurcado com o reticulado ao acaso, de calibre moderado a fino e curso sinuoso, fazendo ângulo de $95^{\circ}$ a $130^{\circ}$ com a veia mediana e ângulo de emergência próximo a $90^{\circ} \mathrm{com}$ as secundárias, bem como sua venação quaternária reticulada poligonal regular, levaram a identificar essa forma fóssil dentro do gênero Nectandra. Muitas feições como: assimetria laminar, microfilia, formato elíptico-oblongo, base aguda assimétrica (convexa no fóssil e ligeiramente côncava no atual), presença, às vezes, de intersecundária curta, venação terciária muito fina em relação à secundária e as características da venação quaternária poligonal regular terminando em seu interior com uma bifurcação (Figura 6C-E) ocorrem também na espécie atual Nectandra megapotamica (Spreng.) Mez. (Lorenzi, 2000b) (ver Figura 6F). Entretanto, esta espécie difere do espécime fóssil por apresentar formato elíptico estreito $(3: 1)$ mais que oblongo; a base aguda cuneada, não ligeiramente convexa e a veia mediana de calibre estreitando-se gradualmente em direção ao ápice. Por essas distinções e pelas mesmas razões já apontadas para Annona sp no que se refere ao desconhecimento de partes anatômicas e reprodutivas para efeito de comparação mais segura e já que se dispõe de somente um espécime o que impede a identificação da variabilidade infra-específica, necessária na designação de uma nova espécie, prefere-se aqui designar esse espécime apenas como Nectandra sp.

\section{CONSIDERAÇÕES FINAIS}

Aspectos paleogeográficos e bioestratigráficos. A subclasse Magnoliidae tem representantes fósseis, seguramente identificados e diversificados, desde o Cenomaniano, con- tudo, o grupo-tronco das angiospermas teria se diferenciado e diversificado, já no Hauteriviano, para dar origem às ninfeales e às várias outras linhagens dentro das magnoliídeas e às monocotiledôneas, segundo Anderson \& Van Wyk (1999).

Como já foi dito, essa subclasse está representada na tafoflora de Aiuruoca pelas ordens Magnoliales (Gênero Annona) e Laurales (Gênero Nectandra).

As Annonaceae teriam surgido, segundo Raven \& Axelrod (1974), no Gondvana Ocidental, durante o início do Cretáceo Superior e, teriam sofrido migrações diretas entre a África e América do Sul, quando esses continentes ainda estavam unidos, alcançando no Paleógeno, a Ásia tropical. Atualmente, dos 122 gêneros existentes, espalhados pela América Tropical, África e Ásia, cerca de 30 gêneros (equivalentes a 25\%) ocorrem no Brasil.

Durante o Paleógeno até o Eoceno Médio, o gênero Annona ocorreu por toda a América do Sul, chegando até a Patagônia. Na Colômbia, sua presença foi detectada através do registro de grãos de pólen (Proxapertites terciaria), no Paleoceno. Van der Hammen \& Garcia de Mutis (1964). No Equador, aparece na flora de Ancón (Santa Elena), conforme Menendez (1971) e Romero (1986). Na Argentina, as Annonaceae estão representadas pelo gênero Annona desde o Paleoceno de Chubut, assim como nas famosas floras do Rio Picheleufú e do Rio Chenqueniyeu (Rio Negro) de idade eocena. No Eoceno Médio aparece, ainda, na flora do Rio Túrbio (Patagônia), conforme Romero (1986).

Esta família está sendo registrada pela segunda vez no Paleógeno brasileiro. Na primeira vez, foram detectados os gêneros Annona e Oxandra, na Bacia de Fonseca, Minas Gerais, em sedimentos de idade eocena média/superior. Oliveira-Silva (1983). Agora, o gênero Annona é registrado em sedimentos de idade eocena/oligocena, da bacia de Aiuruoca, no mesmo Estado.

Durante o Neógeno, a América do Sul se comportou como um centro de dispersão de Annonaceae em direção à América do Norte. Entretanto, as formas mais antigas, norte-americanas (paleógenas) parecem ter sido oriundas da África. Raven \& Axelrod (1974).

A família Lauraceae possui 3.000 espécies em distribuição tropical e subtropical em todo o mundo , especialmente nas florestas centro e sul-americanas. Joly (1998).

As Lauraceae, semelhantemente às Annonaceae, teriam surgido no Gondvana Ocidental, mais especificamente na América do Sul, segundo Raven \& Axelrod (1974). Elas, provavelmente, surgiram durante o Cenomaniano, ou seja, na época da dispersão das magnoliídeas. Anderson \& Van Wyk (1999). Esta família é registrada desde o Cretáceo Superior da Argentina. Romero (1986). No Paleógeno, já estaria presente na Austrália com sete gêneros dos quais o mais proeminente seria Cinnamomum. Por isso a flora terciária australiana é conhecida como "flora de Cinnamomum” Hill (1986).

Possuem, atualmente, mais representantes na Ásia Tropical que na América, provavelmente por um problema de vicariância, conforme Raven \& Axelrod (1974). 
Na América do Sul, as Lauraceae se distribuíam conforme atesta o documentário fóssil paleógeno, desde a Venezuela até a Patagônia. Entre seus fósseis foram reconhecidos os gêneros: Acrodiclidium, Cryptocarya, Nectandra, Persea, Phoebe, Ocotea e Notophoebe. Romero (1986).

O gênero Nectandra aparece, em tafofloras argentinas, no Eoceno Inferior do Rio Picheleufú. Berry (1938 in Menendez, 1971) e no Eoceno Médio do Rio Túrbio. Hünicken (1967). No Eoceno Superior da Venezuela, aparece em Maracaibo. Romero (1986). No Brasil, está sendo pela primeira vez detectada em sedimentos paleógenos, na bacia de Aiuruoca.

Aspectos paleoecológicos e paleoclimáticos. Dentre as espécies atuais de anonáceas, a espécie Annona cacans é a que oferece melhor comparação com a forma foliar estudada. Essa espécie caracteriza-se como forma típica da floresta pluvial atlântica, com espécimes esparsos em florestas latifoliadas semidecíduas até altitudes acima de $900 \mathrm{~m}$, conforme Lorenzi (2000). Portanto, a presença do gênero Annona, durante o Eoceno, por toda a América do Sul até latitudes altas da área patagônica, seria uma das evidências do domínio de um clima tropical úmido naquela época. A presença desse gênero na tafoflora de Aiuruoca também evidencia a existência do ecossistema pluvial atlântico, em área hoje incluída no domínio de floresta pluvial baixo-montana, com estação seca prolongada, situada nos morros mamelonares que constituem os contrafortes ocidentais da Serra da Mantiqueira, segundo Rizzini (1997:377-380), caracterizando para essa área, um clima mais úmido que o atual.

Annona sp, por características tais como: área foliar mesofila, margem inteira, ápice retuso, textura foliar papirácea, lâmina foliar glabra, mostra-se como um vegetal típico de floresta pluvial úmida, que medrou em meio esciofítico ou à luz difusa, portanto, à sombra de espécies mais altas.

A espécie vivente Nectandra megapotamica é a que oferece maior semelhança com a forma fóssil de laurácea, ora estudada, e tem também como preferência ecológica a floresta pluvial atlântica. Nectandra sp., por características tais como: margem inteira, textura papirácea, lâmina foliar glabra, é um gênero sugestivo do mesmo ecossistema de Annona sp.. Contudo, sua área foliar microfila permanece como uma evidência de sua participação no dossel, como elementos emergentes, com exigências luminosas heliófitas.

\section{AGRADECIMENTOS}

As autoras desejam consignar seus sinceros agradecimentos aos revisores do manuscrito pelas excelentes sugestões e correções apresentadas. Também agradecem à Maria Cristina de Castro-Fernandes, pelo dedicado e minucioso trabalho de digitação do texto e a Artur Almgren Saldanha Jr., pelo valioso auxílio de informática prestado na confecção das figuras. Aos laboratórios de Geociências (UnG) e de Paleobotânica e Palinologia do Instituto de Geociências (USP) agradecem pela disponibilidade dos equipamentos.

\section{REFERÊNCIAS}

Ash, A.; Ellis, B.; Hickey, L.J.; Johnson, K.; Wilf, P. \& Wings,S. 1999. Manual of leaf architecture- morphological description and categorization of dicotyledonous and net-veined monocotyledonous angiosperms. $1^{\text {a }}$ ed.Washington DC, Smithsonian Institution, 65 p.

Anderson, J.M. \& Van Wyk, B. 1999. The Higher Plants. In: J. M. Anderson (ed.) Towards Gondwana Alive, Gondwana Alive Society, p. 52-57.

Cronquist, A. 1988. An integrated system of classification of flowering plants. Nova Iorque, Columbia University Press, $1262 \mathrm{p}$.

Duarte, L. 1958. Annonaceae fósseis da bacia terciária de Fonseca. Belo Horizonte, Departamento Nacional da Produção Mineral, Divisão de Geologia e Mineralogia, 27 p. (Boletim 178).

Dutra, T. \& Stranz, A 2002. Clarificação e diafanização de folhas. In: T.L. Dutra (ed.) Técnicas e Procedimentos de trabalho com fósseis e formas modernas comparativas, Editora Unisinos, p. 27-29.

Foster, A.T. 1952. Foliar venation in angiosperms from an ontogenetic standpoint. American Journal of Botany, 37:159-171.

Franco-Delgado, S.G. 2002. Tafoflora paleógena da Formação Entre-Córregos, bacia de Aiuruoca, Estado de Minas Gerais, Brasil. Centro de Pós-graduação/Pesquisa/Extensão, Universidade Guarulhos, Dissertação de Mestrado, 131 p.

Garcia, M.J.; Santos, M. dos \& Hasui, Y. 2000. Palinologia da parte aflorante da Formação Entre-Córrego, bacia de Aiuruoca, Terciário de Minas Gerais, Brasil. Revista Universidade Guarulhos (Geociências), 5(suplem.):259.

Hickey, L.J. 1979. A revised classification of the architecture of dicotyledonous leaves. In: C.R. Metcalfe \& L.W. Chalk (eds.) Anatomy of the dicotyledons, Clarendon Press, 1: 25-39.

Hickey, L.J. \& Wolfe, J.A. 1975. The bases of angiosperm phylogeny: vegetative morphology. Annals Missouri Botanical Garden, 62: 538-589.

Hill, R.S. 1986. Lauraceous leaves from the Eocene of Nerriga, New South Wales. Alcheringa, 10 (4): 327-352.

Hünicken, M. 1967. Flora terciária de los estratos de Rio Túrbio, Santa Cruz. (Niveles plantíferos del Arroyo Santa Flavia). Revista Facultad de Ciencias Exactas, Físicas y Naturales, Universidad de Córdoba, Série Ciencias Naturales, 27(3/4): 139-227.

Joly, A.B. 1998. Botânica - Introdução à taxonomia vegetal. $12^{\mathrm{a}}$ ed. São Paulo, Editora Nacional, 777 p.

Lorenzi, H. 2000a. Árvores brasileiras . Manual de identificação e cultivo de plantas arbóreas do Brasil. São Paulo, Instituto Plantarum de Estudos da Flora Ltda, 2 v., 720 p.

Menendez, C.A. 1971. Floras terciárias de la República Argentina. Ameghiniana, 8(3/4):357- 371.

Oliveira-Silva, M.I.M.N. 1983. Flórula da bacia de Fonseca, Minas Gerais, Brasil. Programa de Pós-graduação em Geologia, Universidade Estadual do Rio de Janeiro, Dissertação de Mestrado, $119 \mathrm{p}$.

Raunkiaer, C. 1934. The use of leaf size in biological plant geography. In: C. Raunkiaer (ed.) The life forms of plants and statistical plant geography, Clarendon Press, p. 368-378.

Raven, P.H. \& Axelrod, D.I. 1974. Angiosperm biogeography and past continental movements. Annals Missouri Botanical Garden, 61:539-673. 
Raven, P.H.; Evert, R.F. \& Eichhorn, S.E. 2001. Biologia vegetal. $6^{a}$ ed. Rio de Janeiro, Editora Guanabara Koogan, 906 p.

Rizzini, C.T. 1997. Tratado de fitogeografia do Brasil. $2^{\mathrm{a}}$ ed. Rio de Janeiro, Âmbito Cultural Edições Ltda., 745 p.

Romero, E.J. 1986. Paleogene phytogeography and climatology of South America. Annals Missouri Botanical Garden, 73:449461.
Santos, M. 1999. Serra da Mantiqueira e Planalto do Alto Rio Grande: a bacia terciária de Aiuruoca e evolução morfotectônica. Programa de Pós-Graduação em Geologia Sedimentar, Universidade Estadual Paulista, Tese de Doutoramento,134 p. Van der Hammen, T. \& Garcia de Mutis, C. 1964. La flora del polen del Paleoceno de Colombia. Boletin Geológico del Servicio Geológico Nacional, 12 (1-3):33-45. 